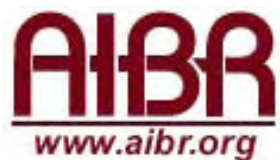

REVISTA DE ANTROPOLOGÍA IBEROAMERICANA

ESTIMADO LECTORIA:

GRACIAS POR DESCARGAR ESTE ARTÍCULO. EL TEXTO QUE ESTÁ A PUNTO DE CONSULTAR ES DE ACCESO LIBRE Y GRATUITO GRACIAS AL TRABAJO Y LA COLABORACIÓN DESINTERESADA DE UN AMPLIO COLECTIVO DE PROFESIONALES.

USTED PUEDE AYUDARNOS A INCREMENTAR LA CALIDAD Y A MANTENER LA LIBRE DIFUSIÓN DE LOS CONTENIDOS DE ESTA REVISTA A TRAVÉS DE SU AFILIACIÓN A LA ASOCIACIÓN AIBR:

http://www.aibr.org/antropologia/aibr/socios.php

La afiliación a AIBR tiene un coste mínimo al año, y le proporcionará las siguientes ventajas y privilegios:

1. Recibir en su domicilio la revista impresa, en Europa y América (tres números anuales), así como todas las novedades relativas al funcionamiento de la asociación.

2. Recibir en su domicilio, a precio especial o de forma gratuita, cuantas publicaciones adicionales edite la asociación.

3. Derecho a voto en las asambleas de socios, así como a presentarse como candidato a la elección de su Junta Directiva.

4. Recibir el boletín de socios (tres números anuales), así como la información económica relativa a cuentas anuales de la asociación.

5. Beneficiarse de las reducciones de precio en congresos, cursos, libros y todos aquellos convenios a los que a nivel corporativo AIBR llegue con otras entidades. En este momento, existen los siguientes acuerdos:

o Reducción de un $20 \%$ en el precio de todos los libros publicados por la editorial MELUSINA.

o Reducción de un $20 \%$ en el precio de todos los libros publicados por la editorial SEPHA.

o Reducción de un 30\% en el precio de todos los libros publicados por la editorial GRAN VÍA.

o Derecho a cuota reducida en los congresos trianuales de la FAAEE (España) y a los bianuales de la Sociedad Española de Antropología Aplicada.

6. Promoción gratuita, tanto a través de la revista electrónica como de la revista impresa, de aquellas publicaciones de las que sea autor y que estén registradas con ISBN. La difusión se realiza entre más de 5.600 antropólogos suscritos a la revista.

7. Cuenta de correo electrónico ilimitada de la forma socio@aibr.org, para consultar a través de webmail o cualquier programa externo.

8. Espacio para web personal de la forma http://www.aibr.org/(directorio)/(nombre) y cuenta propia de ftp.

9. Acceso con clave a todos los documentos de la Intranet de socios de AIBR, incluida la consulta a artículos en proceso de evaluación de la revista AIBR.

10. Promoción gratuita a través de la revista (banner rotativo y reseña) de aquellos eventos, congresos, conferencias o cursos en los que usted forme parte del comité organizador.

11. Opción a formar parte como evaluador de los artículos recibidos por la revista.

IMPORTE DE LA CUOTA ANUAL: Hasta diciembre de 2008, la cuota única anual es de 32 (euros). Su validez es de un año a partir del pago de la cuota. Por favor, revise la actualización de cuotas en nuestra web.

PARA HACERSE SOCIO DE AIBR, POR FAVOR, CONSULTE LA SIGUIENTE DIRECCIÓN:

http://www.aibr.org/antropologia/aibr/socios.php 


\title{
A138 transformaciones uRbanas en EL www.aibr.org SECTOR SUR DEL BARRIO PORTEÑO DE PARQUE DE LOS PATRICIOS: DE ESPACIO VACÍO A RECURSO
}

\section{Ana Gretel Thomasz}

Universidad de Buenos Aires

\begin{abstract}
Resumen
En este artículo analizamos las transformaciones socio-urbanas que están desarrollándose en un subsector de un barrio del sur de la ciudad de Buenos Aires (Parque de los Patricios) en vinculación con la edificación de un complejo habitacional por parte de una cooperativa de vivienda conformada por un movimiento político social de trabajadores desocupados. Exploramos las tensiones y disputas suscitadas entre los vecinos ya establecidos en dicho sector y el movimiento político social citado por el control del espacio urbano local. Describimos la transformación del espacio urbano en cuestión en un recurso a partir de su condición inicial de espacio vacío. Vinculamos tales transformaciones con otras más amplias que vienen produciéndose en el seno de la ciudad de Buenos Aires desde el último decenio del siglo XX aproximadamente, relativas al incremento de la segregación y la fragmentación socio-espacial, la crisis de la urbanidad y el resquebrajamiento del vínculo social.
\end{abstract}

\author{
Palabras clave \\ Espacio urbano, espacio vacío, recurso, urbanidad.
}

\section{URBAN TRANSFORMATIONS IN THE SOUTH SECTOR OF THE PORTEÑO DISTRICT IN THE PARQUE DE LOS PATRICIOS: FROM EMPTY SPACE TO RESOURCE}

\begin{abstract}
This paper analyzes the social and urban changes occurring in a neighborhood in the South Sector of Buenos Aires (Parque de los Patricios). The changes are connected to the construction of a housing complex by a cooperative established though a social political movement of unemployed workers. We explore the struggles for the control of the local urban space, between this political movement and the neighbors who were already living in the neighborhood. We describe the transformation of this urban space from empty space to a resource. We relate such changes to others that have been developing in the city of Buenos Aires during the last decade of the 20th century, such as increased segregation and fragmentation of the social space and the weakening of existing social ties.
\end{abstract}

Key words

Urban space, empty space, resource, urbanity. 
Recibido: 16 de mayo de 2008

Aceptado: 15 de julio de 2008

\section{Introducción y metodología}

as reflexiones que aquí presentamos son parte de la investigación de
campo que venimos desarrollando en el marco de la tesis doctoral en
antropología en un subsector del barrio de Parque de los Patricios (Ciudad de Buenos Aires), al que denominamos "zona X"1. Dicha investigación toma como trasfondo las transformaciones urbanas que vienen desarrollándose en la ciudad de Buenos Aires desde el último decenio del siglo XX aproximadamente, mientras que tiene como principal propósito examinar el proceso de reestructuración urbano desplegado en la zona $X$ a raíz de la llegada y el establecimiento de un movimiento político social "piquetero"2 -llamado "Movimiento Territorial de Liberación" (MTL de aquí en adelante)- a fin de construir un complejo habitacional a través de un programa autogestionario de edificación de viviendas de interés social denominado "Programa de Autogestión para la Vivienda" (PAV de aquí en adelante). El proceso de edificación del conjunto habitacional estuvo a cargo del MTL y se extendió a lo largo del período 2004-2007. En ese lapso, hemos efectuado actividades de observación participante en el lugar en construcción y entrevistas no estructuradas a los integrantes del MTL, y así como asisitido a múltiples reuniones y eventos ofrecidos por la agrupación. Al mismo tiempo, realizamos entrevistas abiertas y semiestructuradas a los vecinos residentes en la zona $X$, y participamos de algunos encuentros y actos de protesta organizados por ellos. En la actualidad, el

\footnotetext{
${ }^{1}$ Nombre ficticio al que acuñamos y utilizamos con el único propósito de referirnos a nuestra zona de interés.

${ }^{2}$ Se conoce como movimientos "piqueteros" a los movimientos de trabajadores desocupados que se difundieron por el interior del país (en ciudades como Tartagal, situada en la provincia de Salta, y Cutral-có, en la de Neuquén) a mediados del último decenio del siglo XX, en vinculación con el colapso de las economías regionales y la privatización acelerada de las empresas del Estado (Svampa y Pereyra 2003). Tales movimientos adoptaron el corte de rutas como modalidad de protesta (clamaban entre otras cosas por fuentes de trabajo). Posteriormente, las agrupaciones piqueteras se desarrollaron también en ámbitos urbanos como la ciudad de Buenos Aires, en donde han sido históricamente rechazados, quizás debido a que en los orígenes, algunas de ellas recurrieron al uso de bastones y pañuelos que les cubrían el rostro en sus actos de protesta.

En líneas muy generales y siguiendo a Svampa y Pereyra (2003:54), podemos clasificar a las organizaciones piqueteras según su origen partidario (aquellas que se conformaron y desarrollaron en el seno de partidos políticos concretos), sindical (aquellas que se gestaron en a partir de centrales sindicales y sus líderes) o autónomo (las que surgieron y se desarrollaron por fuera de los partidos políticos y sindicatos).
} 
trabajo investigador se centra en los modos de vinculación y las interacciones sociales que se desarrollan entre éstos últimos -es decir, los vecinos establecidos en la zona $X$ desde hace décadas- y los miembros del MTL residentes en el conjunto habitacional instalados en la zona $X$ de manera reciente.

Para efectuar el presente análisis retomamos algunas de las contribuciones y planteamientos realizadas por Elias y Scotson en el ya clásico trabajo titulado Los establecidos y los outsiders, que recoge los resultados de una investigación desarrollada hacia finales de la década del cincuenta del siglo XX en una pequeña comunidad industrial de Inglaterra cercana a Leicester bautizada por los autores con el nombre ficticio de Winston Parva (Elias y Scotson,2000; Neiburg, 2000). El centro de interés de la investigación se encuentra en las diferencias de poder existentes entre dos grupos sociales que comparten un mismo espacio urbano; diferencias de poder que son vinculadas por los autores con el tiempo diferencial que ambos grupos llevan residiendo dicho espacio, pero también -y fundamentalmente- con el distinto grado de integración, cohesión interna y organización observable en cada una de ellos. De este modo, los autores examinan las formas de relación predominantes entre dos grupos sociales -los vecinos "establecidos" en Winston Parva "desde antiguo" y los recién llegados o "outsiders"- cuyos miembros no difieren en otros aspectos (pertenencia a clase social, credo religioso, nivel de instrucción, nacionalidad) más que los mencionados. Como lo ha destacado el propio Elias, el trabajo posee la enorme virtud de poner de manifiesto las limitaciones de las que adolece cualquier teoría que intente explicar las diferencias de poder en función de ciertos factores exclusivamente, como la posesión o no posesión de bienes materiales (medios de producción, armas), y de destacar la trascendencia que al respecto suelen adquirir otros elementos como los lazos informales que unen y cohesionan a los miembros de un grupo social, sus niveles de integración y solidaridad interna ${ }^{3}$ y su potencial organizativo.

\footnotetext{
${ }^{3}$ En efecto, la investigación muestra que eran esos los factores que en Winston Parva hacían posible que un número pequeño de familias establecidas accediera y monopolizara un número elevado de cargos en las principales instituciones de la comunidad y que gozara y detentara el poder asociado con dichos cargos, excluendo a las familias de outsiders.
} 


\section{La ciudad de Buenos Aires: transformaciones urbanas recientes}

"Buenos Aires, en los noventa, no sólo ha entrado nuevamente en uno de esos fabulosos y complicados momentos de modernización, sino que, por añadidura, puede decirse que ha iniciado un verdadero giro epocal, ya que se modifican tendencias de larga duración". (Gorelik 2004:208)

La drasticidad de los cambios operados en la ciudad de Buenos Aires desde el último decenio del siglo $\mathrm{XX}$, en el contexto de agudización del proceso de globalización y declive de la economía basada en la producción industrial, condujo a algunos autores (Aguilar 2005; Cicolella 1999; Gorelik, 2004; Mongin, 2006; Prevot Schapira, 2000) a hablar de "crisis urbana" y de la emergencia de un nuevo modelo urbano en la metrópolis, que habría sustituido a aquél bajo el cual se estructuró la ciudad moderna industrial. El surgimiento y la consolidación de nuevas centralidades y el incremento de la segregación y la fragmentación socio-espacial, serían algunos de los rasgos definitorios de ese nuevo modelo. Así, si apenas un par de décadas atrás, Buenos Aires constituía una ciudad relativamente inclusiva, integrada y cohesionada pero actualmente se caracterizaría por su carácter expulsivo y por la tendencia a la fragmentación. Como sostiene Prevot Schapira (2000) este último término supone que aquello que debería tener "un funcionamiento global" ha estallado en múltiples unidades, y que ya no existe "una unificación del conjunto urbano". Siguiendo a Girola (2007) designa además el pasaje de un modelo de ciudad "compacta y orgánica" a uno de ciudad "dispersa y estallada", constituida por "retazos urbanos" sin ningún tipo de vínculo entre sí.

Atendiendo a ese conjunto de fenómenos, algunos autores (Aguilar, 2005; Ciccolella, 1999; Sarlo, 1996) se refieren a una "ghettización" de la ciudad o a la conformación de una "ciudad dual", con áreas gentrificadas ${ }^{4}$ coexistiendo junto a

\footnotetext{
${ }^{4}$ El concepto de "gentrificacion", formado a partir del término gentry (nobleza) fue utilizado por primera vez por Ruth Glass para referirse al proceso observado en Londres, por el cual diversos barrios obreros de la ciudad fueron invadidos por las clases medias y las modestas viviendas obreras, al expirar los contratos de alquiler, adquiridas por los sectores medios y transformadas en elegantes y costosas residencias. Actualmente, el uso del concepto se ha extendido y en términos amplios alude a los procesos de reestructuración por los que atraviesan algunas zonas urbanas opacas o degradadas, procesos que generan un reordenamiento del espacio, sus imágenes y población, produciendo un efecto de atracción sobre grupos de recursos socioeconómicos medios y altos, quienes establecen en las mismas sus lugares de residencia o de actividad comercial o profesional (cfr. O’ Connor y Wyne, 1997).
} 
"enclaves de la pobreza". La imagen de una ciudad dual alude, en efecto, a las repercusiones que la "polarización económica" tiene en la "geografía y ecología urbanas", al tiempo que subraya la emergencia de "nuevas desigualdades", producto de "la retirada" del Estado de Bienestar (Auyero, 2001) y de la intensificación del proceso de globalización. Apela, en suma, a la proliferación de espacios urbanos opulentos, embellecidos, recualificados o gentrificados en los que residen sectores de clase media-alta conectados a la economía global ${ }^{5}$, junto a la desvalorización, el empobrecimiento, el deterioro y la marginación de otros espacios que aparecen entonces como residuales y que son habitados por los sectores sociales más pauperizados.

Refiriéndose de igual modo a la consolidación de un nuevo modelo urbano en Buenos Aires y al incremento de la fragmentación, Gorelik (2004) puntualiza tres tipos de cambios de "inusual radicalidad" acaecidos en la metrópolis, entre los que nos interesa destacar la "crisis del espacio público"6, fenómeno al que el autor vincula con el creciente empobrecimiento de las clases medias y bajas, la progresiva naturalización del paisaje "de la fractura social y urbana" por parte de amplios sectores de la sociedad, el debilitamiento del imaginario de una ciudad inclusiva y la disolución del horizonte de la integración y la perspectiva del ascenso social (Gorelik, 2004:208). Según Gorelik, la magnitud y el significado de esta crisis sólo se vuelve entendible si se tiene en cuenta que el espacio público constituye "el tablero político-urbano" que hace posible la aparición de lo diferente, así como "el lugar plural" que favorece tanto el conflicto como una potencial integración social, política y cultural (Gorelik 2004:211).

\footnotetext{
${ }^{5}$ A modo de ejemplo pueden citarse los casos del nuevo barrio de Puerto Madero y la revitalización del viejo barrio del Abasto, y de algunos sectores de los barrios de San Telmo y La Boca como al área aledaña a la Plaza Dorrego en el caso del primero y al Pasaje Caminito y la calle Magallanes en el del segundo. Es importante subrayar que la recualificación de estos espacios ha redundado, en mayor o menor medida, en la segregación socio-espacial de los sectores de menores recursos, tal como lo han mostrado distintas investigaciones (Carman, 2006; Herzer, 2004; Lacarrieu, 2007).

6 Los otros dos cambios identificados por Gorelik son la declaración de la autonomía de la ciudad (1996), hecho por el cual se sancionó su Constitución y la ciudadanía comenzó a elegir su Jefe de Gobierno en forma directa, y la "urbanización del capital", que alude a la irrupción y novedosa participación de importantes capitales privados en iniciativas que afectan sectores urbanos de escala territorial. Según el autor, contrariamente a lo que ocurre en el contexto contemporáneo, a lo largo del proceso de estructuración de la ciudad moderna la inversión privada no produjo intervenciones concentradas de gran magnitud ni capacidad de configurar ciudad, mientras que en las oportunidades en que intervino lo hizo siempre bajo la guía o regulación pública (Gorelik, 2004:209).
} 
Buenos Aires se ha convertido en una ciudad desintegrada, desmembrada y fracturada también en la visión de Mongin (2006). En consonancia con el enfoque de Gorelik, el autor enlaza la intensificación de la fragmentación con la desaparición o el adelgazamiento de los estratos medios, "que eran la argamasa de la solidaridad entre las clases sociales" (Mongin, 2006:266). La caída brutal de un amplio sector de la clase media es un elemento decisivo en la reconfiguración del territorio y su fragmentación.

Todos los fenómenos citados -incremento de la segregación y la fragmentación socioespaciales, "ghettización" o dualización de la ciudad, empobrecimiento y desintegración de la clase media, disolución de la perspectiva del ascenso social, crisis del espacio público- han provocado su impacto en una urbe que, como Buenos Aires, se constituyó tras un férreo precepto de "progreso civilizatorio" y se forjó en los imaginarios sociales como "fuertemente homogénea e integrada" (Lacarrieu, 2005). Pero esos fenómenos no sólo conmovieron la imagen de Buenos Aires como una urbe "blanca y europea" (López, 2003) y su reputación de "la París Latinoamericana" sino que fundamentalmente, han puesto en cuestión la capacidad de la ciudad para "hacer sociedad" (Donzelot, 2004), aglutinar y cohesionar, así como la posibilidad de sus habitantes de pensarla como una unidad y de pensarse a sí mismos como miembros de un solo colectivo social.

Por último, cabe remarcar que otros autores (Girola, 2007; Lacarrieu, 2005) son más escépticos a la hora de aceptar la tesis de la fragmentación de la ciudad y de la consolidación de un nuevo modelo urbano en Buenos Aires. Así, para aludir a los cambios acontecidos en la metrópoli de manera reciente, Lacarrieu opta por hablar de "recorridos" antes que adoptar el lenguaje de la fragmentación. Más específicamente, de "recorridos del progreso" y "recorridos de la crisis". Los primeros se asocian a los itinerarios dibujados por la conexión de los espacios estetizados y gentrificados. Los segundos remiten a aquellos circuitos que es posible trazar conectando los sitios en los que se concentran la indigencia y la pobreza, se desarrollan actividades vinculadas a la supervivencia y se expresa o escenifica la protesta social, los que son apropiados por actores sociales como cartoneros, piqueteros, vendedores ambulantes y otros. 


\section{El Movimiento Territorial de Liberación (MTL) y el Programa de Autogestión para la Vivienda (PAV).}

El MTL se autodefine como un movimiento político, social y territorial de lucha por la tierra y la vivienda y no solamente como una agrupación de trabajadores desocupados o "piquetera". Constituye un movimiento político social partidario en el sentido de que se encuentra ligado al Partido Comunista Argentino. Se conformó formalmente en 2001. En la ciudad de Buenos Aires, la agrupación nació y se expandió en estrecha relación con la profundización de la crisis habitacional producida en el último decenio del siglo XX (Thomasz, 2007). De hecho, creció reafirmando el derecho de los sectores populares a acceder a una vivienda "digna y definitiva", y en torno al designio de crear soluciones habitacionales para sectores en situación de emergencia en ese sentido: familias residentes en inmuebles ocupados bajo amenaza de desalojo, inquilinatos, hoteles-pensión, villas o asentamientos. En efecto, la mayor parte de las familias que pertenecen al movimiento carecen de vivienda propia, por lo que cubren su necesidad de alojamiento y hábitat a través de alguna de las modalidades citadas. A su vez, la mayor parte de sus integrantes residen en la región sur y sudoeste de la ciudad de Buenos Aires, en los barrios de La Boca, Barracas y Constitución, y Flores y Mataderos, por citar algunos ejemplos. Por otro lado, gran parte de sus miembros son inmigrantes de países limítrofes o latinoamericanos como Perú, Bolivia, Paraguay, Chile y otros (cfr. Thomasz, 2007).

Tras su proceso de lucha, movilización y organización, el MTL logró que el Instituto de Vivienda ${ }^{7}$ de la Ciudad de Buenos Aires le extendiera un crédito a través del PAV para edificar un conjunto habitacional en la zona X. EI PAV, creado a instancias de la ley $341 / 00$, tiene como objetivo instrumentar políticas de acceso a la vivienda para hogares de escasos recursos y prioriza la extensión de créditos a personas que se hallen "con sentencia judicial de desalojo" y que se nucleen en organizaciones mayores como cooperativas de vivienda a los fines de recibirlo (ley 341, art. 6). Éste último -la organización en una cooperativa de vivienda y construcción- fue el camino seguido por el MTL. Cabe remarcar que dado el carácter

\footnotetext{
${ }^{7}$ El Instituto de Vivienda es el organismo responsable de ejecutar las políticas de vivienda en el ámbito de la ciudad. Fue creado en 2003 en reemplazo de la antigua Comisión Municipal de la Vivienda y es la entidad que la continúa jurídicamente.
} 
autogestionario del programa, el Instituto de Vivienda de la Ciudad sólo se ocupa de extender los fondos a las cooperativas, dejándolas luego en situación de conducir y llevar adelante el proceso de edificación de la obra.

\section{La zona X como espacio vacío.}

La zona $X$ puede ser caracterizada como un gran fragmento o espacio urbano residual, desvalorizado y "relegado" (Donzelot 2004; Mongin 2006), poblado por clase media empobrecida sin mayores esperanzas "de reascenso social" (Kessler, 1998). Se trata de uno de esos espacios devaluados y desindustrializados que han devenido casi obsoletos en el contexto de la globalización y que representan la contracara de los espacios urbanos recualificados. Se sitúa en el sector sudoeste del barrio porteño de Parque de los Patricios. Linda hacia el norte con el extenso espacio verde llamado Parque de los Patricios -del que el barrio toma su nombre-, hacia el sudoeste con el empobrecido barrio de Nueva Pompeya, y hacia el sudeste con el también empobrecido barrio de Barracas.

\footnotetext{
${ }^{8}$ Para Donzelot (2004) y Mongin (2006), las ciudades contemporáneas pueden ser pensadas en términos de una triple fractura o partición que se corresponde con tres movimientos o velocidades diferenciadas: la gentryfication, la periurbanización y la relegación. Aunque con el término relegación los autores apelan, stricto senso, a los procesos de "ghettización", aislamiento y deterioro que pesan sobre los grandes conjuntos habitacioneales construidos por el poder público desde mediados del siglo XX en los suburbios de importantes ciudades francesas como París y Lyon (en la actualidad habitados en su mayoría por extranjeros y minorías étnicas y caracterizados por su acentuada conflictividad social); Mongin lo ha aplicado también en un sentido más amplio y lato para referise a ciertos espacios urbanos degradados de ciudades del tercer mundo, como la villa 31 en Buenos Aires. Es en este sentido lato, de espacio urbano deteriorado, de infraestructura obsoleta, escasamente intervenido y mantenido por el poder público, que utilizamos la noción de relegación para caracterizar a la zona $\mathrm{X}$.
} 


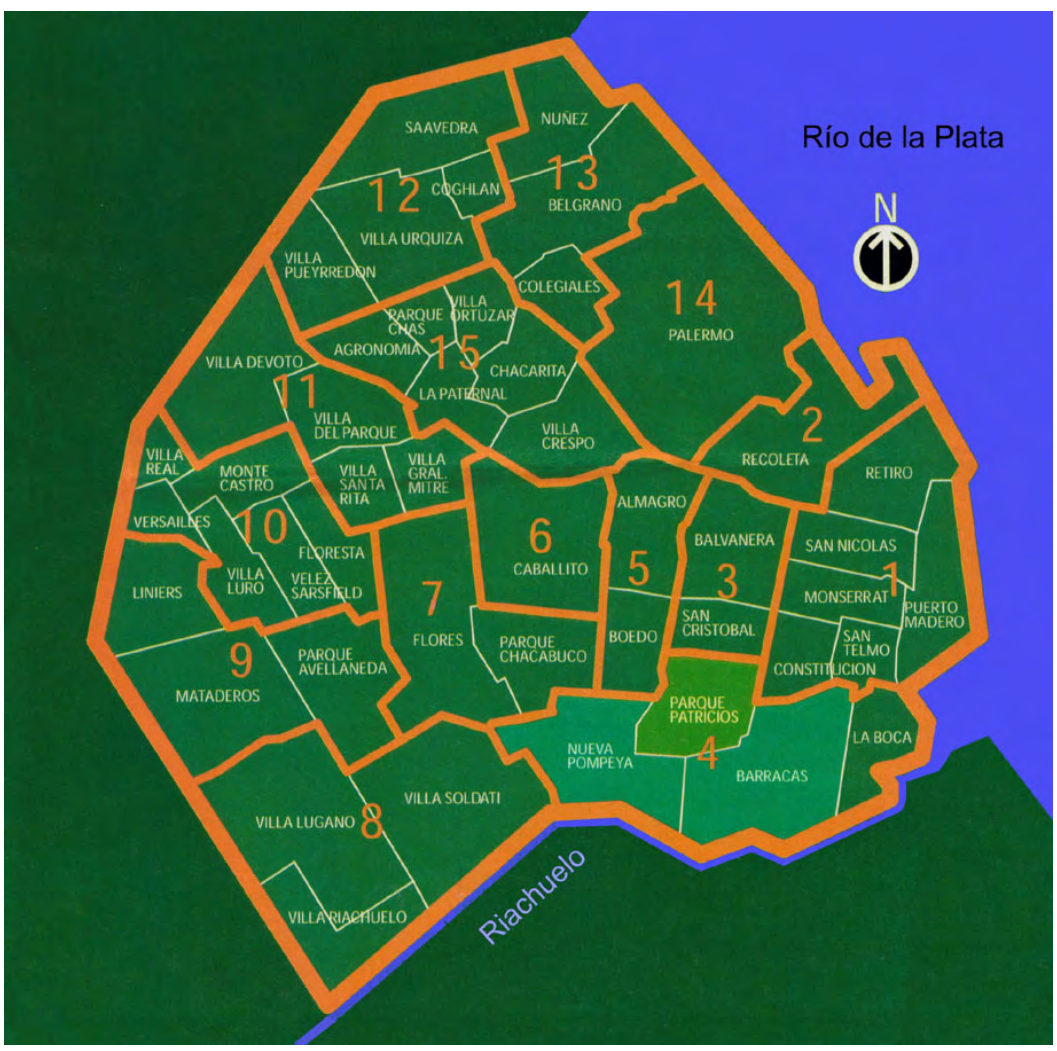

IMAGEN 1. Ciudad de Buenos Aires y sus 47 barrios. Fuente: Gobierno de la ciudad de Buenos Aires.

Más específicamente, por el sur, la zona X desemboca en una extensa villa conocida como villa 21-24, en el seno de la cual corre el Riachuelo. Más específicamente aún, por el sur, desemboca directamente en un subsector de la villa 21 conocido como "barrio Zavaleta", en cuyas proximidades se encuentra un espacio perteneciente a una entidad pública creada por la última dictadura militar (19761983) denominada "Cinturón Ecológico Area Metropolitana Sociedad del Estado" (C.E.A.M.S.E) ${ }^{9}$. Cabe destacar que en el curso del último lustro, el barrio Zavaleta se ha ganado la reputación de ser el más peligroso de la villa 21 , dado que allí se distribuye y comercializa una sustancia popularizada con el nombre de "Paco" o "pasta base de cocaína", una de las drogas más dañinas y de negocio más lucrativo consumidas actualmente en el ámbito de la ciudad, y por esta ultima razón muy codiciada entre los jóvenes de bajos recursos económicos.

\footnotetext{
${ }^{9}$ Se trata de un organismo público que fue creado para la deposición de los residuos del área metropolitana de Buenos Aires a través del sistema de relleno sanitario; el que sustituyó al anterior y contaminante sistema de incineración de los desechos.
} 


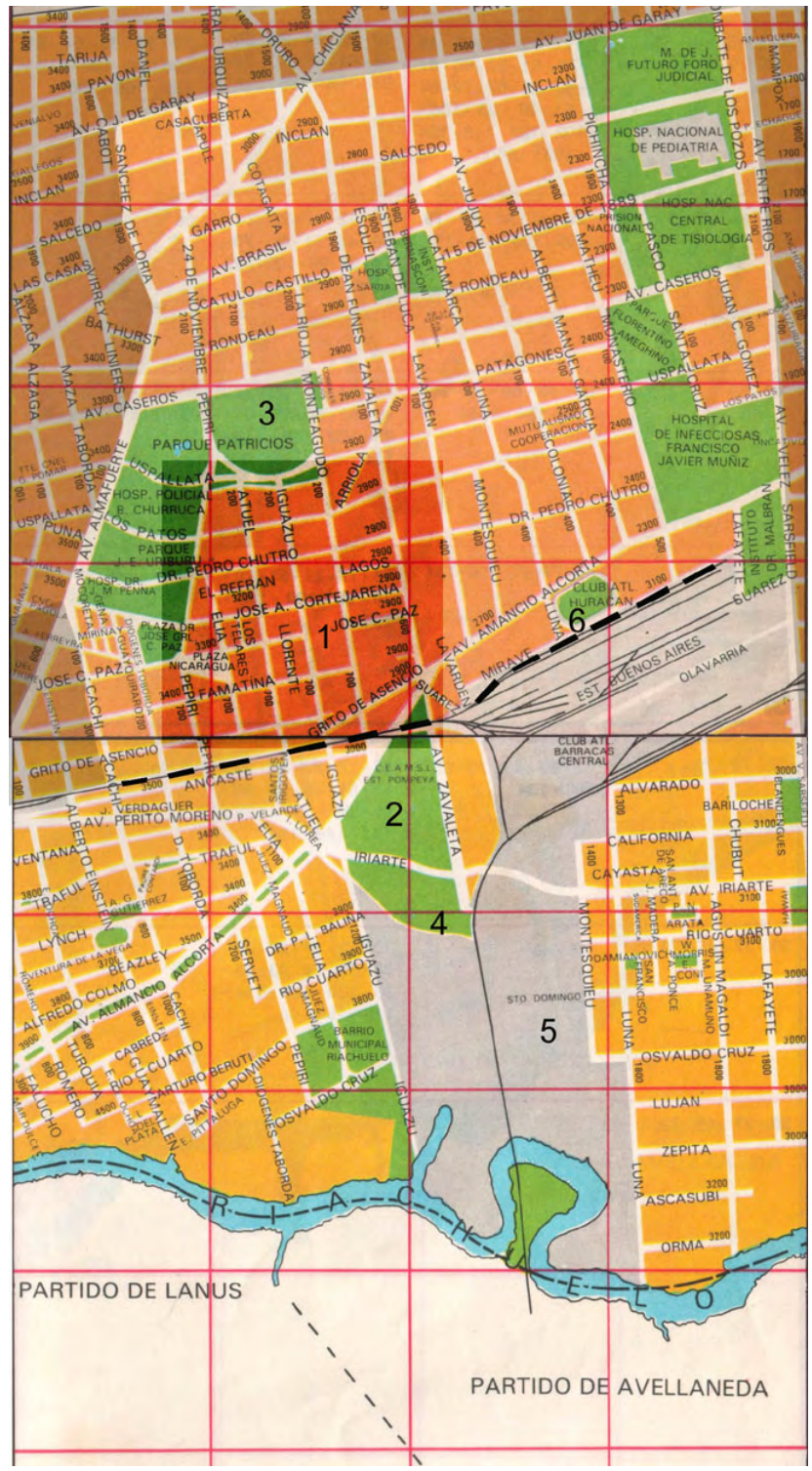

IMAGEN 2. Plano del barrio de Parque Patricios y la zona X. La zona X corresponde al espacio resaltado en el centro de la imagen. La zona sombreada y la línea punteada señalan los límites del barrio de Parque de los Patricios.

Fuente: Guía T Capital Federal, 1994
1. Complejo habitacional MTL
2. CEAMSE
3. Parque de los Patricios
4. Barrio Zavaleta
5. Villa 21-24
6. Club Atlético Huracán

Hasta hace poco más de tres años, la zona X constituía una zona olvidada, simbólicamente distanciada del resto del barrio de Parque Patricios. Configuraba uno de esos "espacios vacíos" a los que, al decir de Bauman, como ciudadanos "generalmente no entramos", "y en los que nos sentiríamos perdidos y vulnerables, 
sorprendidos, alarmados y hasta un poco asustados ante la vista de otros seres humanos" (2002:113).

Aún en la actualidad constituye una región notoriamente diferenciada del entorno urbano-barrial en el que se encuentra inserta: se erige sobre terrenos o "bajos" antiguamente bañados por las aguas del Riachuelo y posteriormente rellenados; su infraestructura y servicios públicos -especialmente los de iluminación y de mantenimiento de aceras- son marcadamente deficientes; y las calles que la atraviesan poseen nombres distintos a las del barrio mayor del que forma parte. Pese a ser la continuación más o menos directa de dichas calles, su nomenclatura se modifica al cruzar dos importantes avenidas locales. Además, hasta allí no llegan los taxis puesto que sus conductores se niegan a circular por el área.

Se trata de una zona gris, opaca, desolada, de muy baja densidad poblacional, débilmente transitada por ciudadanos no residentes en ella y por automóviles; y en la que predominan las casas bajas, viejas, deterioradas y en muchos casos vacías así como los galpones y los ex establecimientos industriales semiabandonados o reconvertidos en depósitos de transportes de carga pesada y expresos, los que se instalaron allí a finales de la década del setenta cuando la zona fue recategorizada como "zona de equipamiento"10.

Los vecinos residentes en el área suelen caracterizarla como una zona "menos urbana" que el resto de Parque Patricios, como una región "apagada", de "poco movimiento", dotada de su "propio ritmo". Constituye de este modo una región "otra", caracterizada por su alteridad con respecto al entorno urbano más amplio del que forma parte. En palabras de una vecina "es un rincón olvidado... nosotros somos los suburbios de Parque Patricios....no somos ni una cosa ni la otra, no es Pompeya pero tampoco es como Parque Patricios para allá" (señala hacia el norte) (Entrevista a ME, Septiembre 2006).

Por otra parte, la zona cuenta con unas pocas instituciones, entre las que se cuentan una sociedad de fomento y una pequeña iglesia. Además, en sus alrededores se encuentra la cancha del club de fútbol más importante del barrio: el Club Atlético Huracán. Otra de sus particularidades es que alberga un hogar destinado a proveer alojamiento a personas mayores sin vivienda carentes de

\footnotetext{
${ }^{10}$ El Código de Planeamiento Urbano de la ciudad de Buenos Aires divide al suelo urbano en tres grandes categorías: zona "residencial", zona "comercial" o zona "de equipamiento". A diferencia de 
recursos económicos ${ }^{11}$, así como un parador nocturno para pernocte de hombres adultos, también "en situación de calle"12, a los que se les ofrece refugio, cama y alimento en forma inmediata por el lapso de una noche"13.

En términos poblacionales, la zona $X$ puede ser caracterizada en términos de una "comunidad de la periferia urbana" (Elias y Scotson, 2000) de la ciudad de Buenos Aires. Se destaca por la escasez de jóvenes y la primacía de adultos y mayores de clase media-baja, muchos de ellos inmigrantes o descendientes de inmigrantes españoles o italianos. Se destaca además por la gran cantidad de vecinos que nacieron y permanecieron allí a lo largo de toda su vida y que fueron heredando sus viviendas de las generaciones anteriores: "acá la mayoría es gente humilde, gente que por sucesión, por herencia fue quedándose con la casa de los padres, de los abuelos" (Entrevista a AE, Septiembre 2006). En efecto, está poblada por un grupo de antiguos residentes y familias cuyos miembros se conocen hace más de una generación, han desarrollado un sentimiento de identidad y pertenencia colectivos y sienten respeto por ciertas tradiciones, valores y usos locales: ser hincha de Huracán, haberse bautizado y haber contraído casamiento en la iglesia local, autodenominarse "quemero" o "ranero"14, son sólo algunas de las costumbres que aglutinan y cohesionan a los vecinos del área.

Como lo sugerimos, hasta hace poco tiempo, dicha zona parecía existir realmente sólo para sus residentes, quienes aun hoy suelen definirla más por lo que fue en el pasado que por lo que es en la actualidad. En efecto, determinados períodos históricos y ciertos acontecimientos -algunos de los cuales se sitúan a caballo entre la historia y el mito ${ }^{15}$ - como "La Quema" y el "Ferrocarril de la basura",

las dos primeras, ésta última categoría habilita el establecimiento de industrias y la edificación de grandes galpones para almacenamiento y depósito de mercaderías.

${ }^{11}$ El hogar pertenece a Cáritas y al Sistema Interparroquial de Ayuda Mutua (SIPAM) aunque recibe también financiamiento del gobierno de la ciudad de Buenos Aires.

${ }^{12}$ Expresión utilizada por el poder público para categorizar a las personas que carecen de vivienda y se encuentran residiendo en la vía pública.

${ }^{13}$ El parador se denomina "Bepo Ghezzi" y depende de la Secretaría de Desarrollo Social de ciudad de Buenos Aires.

${ }^{14}$ Se conoce como "quemeros" a los hinchas del club Huracán. El apodo alude a un sitio hoy desaparecido de la zona X en el que se incineraban los desechos de la ciudad, llamado la "Quema de la basura". Sobre este punto y el sentido del apodo "ranero" nos explayamos en los próximos párrafos.

${ }^{15}$ Sobre algunos hechos históricos como por ejemplo la instalación de "La Quema de la basura" hacia finales del siglo XIX y el surgimiento del barrio de "Las latas" en sus alrededores, se han construido tradiciones y ciertos mitos de origen, entre los que se cuenta el supuesto nacimiento del tango en "los prostíbulos del barrio de Las Latas", según los relatos de algunos vecinos. 
y los barrios de "Las latas y de "Las ranas", han dejado una profunda impronta en el imaginario de la población local.

El "Ferrocarril de la basura" (1873-1895) se creó a fines del siglo XIX respondiendo a la necesidad de trasladar los residuos de la ciudad a una zona en la que pudieran ser incinerados. Su recorrido concluía en la estación denominada "La Quema de la basura", que se localizaba en el rincón sudeste de actual zona X, en el predio ocupado hoy por el CEAMSE (ubicado entre las calles Zavaleta y Amancio Alcorta). En cuanto al barrio de "Las Latas", fue el nombre con el que se popularizó el asentamiento que no tardó en expandirse en la zona aledaña a "La Quema de la basura", a la que acudían decenas de indigentes o "cirujas" en busca de desechos para procurarse la subsistencia. El barrio de "Las ranas", por último, se localizaba en el centro de la actual zona $X$ y fue llamado así porque por su cercanía al Riachuelo se inundaba a menudo, causando la difusión de sapos y ranas. De allí el apodo de "raneros" con que se conocía a sus habitantes, quienes, según se comenta, solían cazar ranas para alimentarse.

El coincidente con la proliferación de industrias y la intensa actividad obrera que supo tener la zona $X$ es otro de los períodos reinvindicado y evocado con cierta nostalgia por la población local. En efecto, muy tempranamente se asentaron en el área industrias subsidiarias de los mataderos que funcionaron en el actual Parque de los Patricios entre 1872 y 1902, como seberías, graserías, saladeros y curtiembres, entre las que se cuentan la ex jabonería Seeber (1890-1915) y la ex curtiembre La Francia Argentina (1890-1960), que llegó a emplear 1500 personas. También hacia 1890 se instaló en la zona X la ex usina de gas del Estado. Posteriormente la actividad industrial fue diversificándose, radicándose industrias de distintas ramas productivas: gráfica (imprentas y papeleras), química, metalúrgica y metalmecánica. Se difundieron las tornerías, las prensas de hojalata, las fábricas de bulones y tornillos, las forjas y fundiciones de estaño, y se radicó una fábrica de amianto y otra de cajas fuertes.

De la mano de los establecimientos industriales fueron multiplicándose las viviendas multifamiliares, pensiones y casas de inquilinato que albergaban a la población que llegaba al área procedente de distintas regiones, atraída por la abundancia de fuentes de trabajo. Proliferaron también las cantinas, fondas y bares, que según se cuenta cerraban en la madrugada. 
En suma, hasta la década del sesenta del siglo XX aproximadamente, la actividad en la zona $X$ era intensa y la densidad poblacional alta. Fue en ese decenio cuando la actividad industrial comenzó a declinar y fue en la década posterior, con la instauración de la última dictadura militar, que dicha actividad se paralizó como consecuencia de la nefasta política económica adoptada entonces, la que condujo a la consabida desindustralización del país. Otro factor que contribuyó a la paralización y el despoblamiento de la zona $X$-aunque en menor medida que el proceso de desindustrialización- fue el proyecto de construcción de una autopista denominada "AU3", la que uniría el norte con el sur de la ciudad, una parte de cuya traza atravesaría por el corazón de la zona X. Aunque el proyecto (diseñado durante la intendencia del Brigadier Cacciatore iniciada en 1976) nunca llegó a materializarse, el temor de algunos vecinos a que sus viviendas fueran expropiadas y demolidas por el poder público tuvo sus consecuencias negativas. Según los relatos de algunos antiguos residentes en la zona $X$; ellos mismos, desconcertados, sin perspectivas de poder permanecer por mucho tiempo más en sus viviendas y temiendo ser expulsados en cualquier momento, dejaron de invertir en el mantenimiento de sus propias casas y de preocuparse por el barrio, contribuyendo indirectamente a su estancamiento y deterioro: "Imaginate, nadie ponía ni un clavo" (Entrevista a AE, Septiembre 2006). Para la misma época, comenzaron a instalarse y difundirse los depósitos de transportes de carga pesada y expresos, que aún hoy abundan en el lugar. Ciertamente, gran parte de las ex fábricas fueron reconvertidas en galpones para alojar a los transportes y realizar las transferencias de las cargas, e incluso múltiples viviendas fueron demolidas con ese fin. Otra de las consecuencias fue la rotura y el notorio deterioro de las calles, veredas y cordones, derivada de la circulación sostenida de transportes de carga pesada en una zona no planificada para ello. Según cuentan algunos vecinos, "acá la destrucción vino en el 78, con Cacciatore". A partir de entonces la zona "quedó muerta" (Entrevista a TE, Abril 2007). Tal es el origen de la gradual invisibilización del lugar.

En síntesis, la confluencia de los acontecimientos brevemente descriptos redundaron en la transformación de la zona X en un "espacio vacío", en el sentido de que Kociatkiewicz y Kostera (1999) le otorgan a la expresión. Es decir, en esa clase de espacios urbanos residuales o "sobrantes" que constituyen los "productos de desecho" de la planificación arquitectónica, los desperdicios que quedan "después 
de que se ha llevado a cabo la tarea de estructuración de los espacios que realmente importan" (Bauman, 2002:112). Se trata de lugares "inaccesibles debido a su invisibilidad" y por ende "no colonizados", o a los que nadie desea colonizar (Bauman 2002:112). Pero a pesar de su condición de desechos, no carecen de función: su función clave es la de mapear y diferenciar los espacios urbanos, la de remarcar su recíproca alteridad. En palabras de Bauman: "para que un mapa tenga sentido algunas áreas de la ciudad deben ser descartadas, ser carentes de sentido y ser poco prometedoras. Recortar esos lugares permite que los demás brillen y estén colmados de sentido" (Bauman 2002:113).

Sin lugar a dudas, la zona $X$ fue un producto de desecho de la política urbana pergeñada por la dictadura, que permitió que otros lugares sí visibilizados por el poder local, como el barrio de San Telmo ${ }^{16}$ y desde luego las autopistas efectivamente construidas (la "25 de mayo" y el tramo sur de la "AU7", por ejemplo), brillaran y resaltaran. En el transcurso del último cuarto del siglo XX, en la coyuntura de agudización del fenómeno de globalización, su deterioro fue acentúandose y profundizándose su carácter de "zona de sombras" (Sassen, 1999). Es decir, su condición de espacio urbano residual, devaluado y relegado. Al mismo tiempo, se intensificó el proceso de descenso social de sus pobladores.

\section{De espacio vacío a recurso y a espacio público: la llegada del $M T L$}

En 1999, se instala e inaugura en la zona $X$ el hogar destinado a cobijar ancianos sin vivienda ni recursos económicos antes nombrado, mientras que a finales de 2003 abre sus puertas el parador nocturno para pernocte de hombres adultos también citado. Pero es el mes de mayo de 2003 el que marca un hito en la zona X. Una de las tantas agrupaciones de trabajadores desocupados o "piqueteras" que se conformaron en el país y en la ciudad en el último decenio, el MTL, "desembarca" allí y se dispone a trabajar en un predio de 14.400 metros cuadrados en el que se erigía una ex fábrica perteneciente a una poderosa e influyente sociedad del país. Sus integrantes comienzan por quemar los pastizales del predio, desratizar e instalar obradores para desmontar los viejos galpones y demoler las

\footnotetext{
${ }^{16}$ El barrio de San Telmo fue embellecido, patrimonializado y decretado "centro histórico" en 1979 por el gobierno dictatorial.
} 
instalaciones fabriles que se levantaban allí, con miras a construir un complejo habitacional de 326 viviendas y capacidad superior a las mil personas, a través del programa de edificación de viviendas de interés social ya nombrado (PAV). Además, la agrupación pinta con sus colores distintivos -el rojo y el negro- la sigla "MTL" en el portón de acceso al predio.

El desconcierto prima entre los vecinos establecidos en la zona $X$, quienes en primera instancia intentan averiguar el significado de la enigmática sigla. Movilizados por el acontecimiento, comienzan a intercambiar información, confrontan versiones. Los rumores están a la orden del día. Dados los estigmas y las representaciones negativas que pesan sobre las agrupaciones "piqueteras" y sobre la categoría "complejo habitacional", una vez confirmada la "peor" de las sospechas (es decir, que una agrupación "piquetera" Ilamada "Movimiento Territorial de Liberación" construiría un complejo habitacional allí), el rechazo de los vecinos establecidos ante los piqueteros se manifiesta abiertamente. Efectivamente, los vecinos no tardan en organizar la reacción, que alcanza su cenit cuando consiguen cortar una avenida localizada en el centro neurálgico del barrio mayor -fuera de la zona X- ante la presencia de algunos medios masivos de comunicación. Se presentan además en la Legislatura de la ciudad, en donde exigen reuniones y "audiencias" con los funcionarios de turno. Su posición es clara: se oponen tajantemente a compartir el espacio urbano con los piqueteros bajo el argumento de que ello redundará en su desvalorización.

Pese a su intransigencia, no logran su objetivo: el crédito al MTL ya ha sido otorgado y la ex fábrica comprada con una hipoteca a favor del Instituto de Vivienda de la ciudad. Pero su "lucha" contra el MTL deja un legado: la zona X, cuya relegación, deterioro e invisibilidad era asumida por sus propios pobladores, deviene repentinamente en objeto de disputas. Comienza a aparecer en los medios masivos de comunicación, primero alternativos, luego hegemónicos. Resultado: la zona $X$ adquiere visibilidad, cobra existencia para el "afuera". En tanto objeto de disputas, adquiere un plusvalor simbólico y deja de ser un lugar invisible. Es decir, deja de ser un "espacio vacío" (Kociatkiewicz y Kostera, 1999). Pierde su condición de residuo o desperdicio de la planificación urbana, de espacio al que nadie desea colonizar, y al menos un sector de la misma se transforma en un lugar codiciado y valorado -por el MTL desde luego, pero también por los vecinos residentes allí desde hace décadas-. 
Como dijéramos, el argumento que fundamenta la hostilidad de los vecinos establecidos a la instalación de los piqueteros en el área es que ello desvalorizará el territorio: así, si antes de la llegada de éstos últimos, los vecinos residentes en el área enfatizaban el dis-valor de la zona $X$, después de ese acontecimiento parecen sostener que de hecho posee un valor, una vez que aseveran que se des-valorizará. Para ello, es menester que un grupo de outsiders la señale, y al hacerlo, dé cuenta de su existencia: efectivamente, basta con que un grupo de extraños pose su mirada en la zona, se interese por ella, logre apropiarse de una porción de la misma y controlarla para que los vecinos establecidos le confieran valor. Paradójicamente, pese a las marchas y movilizaciones de éstos últimos contra el MTL, la llegada de la agrupación fue condición de posibilidad de la transformación de la zona $X$ de "espacio vacío" en "recurso", en el sentido que Signorelli (1999) le da al término.

Como sostiene la autora, el espacio humano no constituye un contenedor indiferenciado o abstracto sino que se define en relación a los seres humanos que lo usan, lo disfrutan, se mueven en su interior, lo recorren, dominan o controlan (Signorelli, 1999:53). En tanto es pasible de ser controlado y dominado, el espacio es también una fuente de poder. De allí la utilidad de considerarlo como un recurso: “...en la condición humana el control de un recurso se vuelve fuente de poder. Como todo recurso, el espacio es fuente de poderes..." (Signorelli,1999:56).

A la par que deja de ser un espacio vacío y deviene en recurso, la zona X va adquiriendo algunas características de espacio público, las que nos llevan a desnaturalizar y relativizar el discurso vecinal acerca su presunta desvalorización: funcionarios del Instituto de Vivienda de la ciudad y otros de mediano y alto rango incluido el Jefe de Gobierno porteño comienzan a "desfilar" por allí, adonde se acercan para visitar la obra en construcción. Ya no es raro ver gente -obreros, administrativos, arquitectos- y no sólo camiones circular por las calles principales del área. El poder público coloca carteles indicativos en las paradas de colectivos, letreros de señalización de las calles y contenedores plásticos para deposición de residuos similares a lo que se encuentran en otras zonas de la ciudad. Además, mejora la iluminación del área próxima al complejo habitacional. Como en otras áreas de la urbe, algunos efectivos de la policía comienzan a custodiar las esquinas. Por otra parte, surgen algunos comercios (un almacén, una pizzería y un kiosko) 
nuevos en la zona aledaña a la de la construcción del complejo habitacional. La presencia de la zona $X$ en los medios masivos se vuelve cada vez más frecuente.

Sin embargo, esos cambios no bastan para hablar de la constitución de un espacio público propiamente dicho. Si las ciudades han sido los lugares por excelencia donde intereses y proyectos culturales diferentes se han enfrentado y han logrado coexistir en forma relativamente pacífica (Giglia, 2000) y en las que los extraños tienen probabilidades de conocerse en tanto que extraños -es decir, sin que "nadie ni nada los presione para que dejen de serlo" (Bauman, 2002:102-104)- y si el espacio público constituye el espacio por antonomasia "de encuentro y diálogo entre opiniones e intereses diferentes" (Giglia, 2000:59), veremos que en la zona X no hay mucho margen para tal diálogo y aceptación.

\section{"Establecidos" y "outsiders"}

Según lo expresamos, el rechazo de los vecinos establecidos a compartir el espacio urbano con el MTL no tardó en expresarse enérgica y abiertamente. De este modo, comenzó a manifestarse una clara división al interior de la zona X entre un grupo de vecinos residentes desde antiguo y un grupo nuevo de (futuros) residentes, que eran tratados por los primeros como seres de un valor humano inferior (Elias y Scotson, 2000:19). Señalamos también que la zona $X$ es habitada por un conjunto de familias cuyos miembros se conocen hace más de una generación, los que en no pocos casos se criaron y crecieron juntos, y quienes han desarrollado un sentimiento de identidad colectivo en base a ciertos símbolos y costumbres. Pues bien, en ese contexto, la afluencia de recién llegados fue sentida por aquellos como una amenaza abierta a su estilo de vida, valores y tradiciones. En consecuencia, abruptamente, la zona $X$ quedó estructurada de acuerdo con un modelo del tipo establecidosoutsiders: aquella figuración humana universal que fuera tan acertadamente descripta y analizada por Elías y Scotson, en la que un grupo de personas integrado y cohesionado, aunque no superior en términos de clase, consigue estigmatizar a otro grupo y denostarlo tratándolo como perteneciente a una especie inferior sobre la base de su tiempo diferencial de residencia en un lugar (Elias y Scotson, 2000:2021). Siguiendo a los autores, para que dicha estigmatización sea posible o efectiva, el grupo de establecidos debe estar instalado en posiciones de poder de las que el 
grupo de outsiders se encuentra excluido, siendo la estigmatización un mecanismo de control social de los primeros para perpetuar su posición dominante, su superioridad e identidad (Elias y Scotson, 2000:23-24).

Pues bien, en la zona $X$, el rechazo de los establecidos a los outsiders fue contundente desde el comienzo y en algunos casos continúa siéndolo en el contexto actual. Así, cuando fueron consultados por el tema, las estigmatizaciones de los vecinos establecidos hacia los piqueteros y el complejo habitacional en cuestión se orientaron en diversos sentidos y revelaron diversos tenores:

\begin{abstract}
"Eso va a ser una villa de cemento" (Entrevista a TE, marzo 2007).
"Las aglomeraciones de gente no son buenas, nunca las grandes aglomeraciones de gente son buenas..." (Entrevista a MAE, septiembre 2006).

"¿Por qué quieren hacer un barrio cerrado"17 acá? Porque eso está todo cercado, todo enrejado. Eso va a ser otro Fuerte $A_{p a c h e}{ }^{18}$. Si ya se sabe que lo de Fuerte Apache no funcionó y que fue un fracaso ¿por qué traer uno acá?" (Entrevista a MRE, marzo 2007).

"El barrio está peor....ahora tenemos el country piquetero, el barrio cerrado" (Entrevista a ARE, septiembre 2006).

“¡Van a poner un hacinamiento al lado de mi casa! ¡La pagué con mi sueldo, la compré con mi trabajo! (...) si yo hago el sacrificio y compré mi casa con mi sacrificio, ¡no tiene por qué venir un arreglo político a poner un hacinamiento al lado de mi casa!" (Declaraciones de VE. Encuentro realizado en la Legislatura de la ciudad de Buenos Aires, abril 2004).
\end{abstract}

Como se desprende de los testimonios, este grupo de vecinos puso el acento en la tipología edilicia de las viviendas, es decir en la categoría "complejo habitacional", la que se encuentra saturada de prejuicios y representaciones negativas. De este modo, comparó a priori y acríticamente al futuro complejo habitacional del MTL con otros construidos hace décadas en otros barrios de la ciudad como "Fuerte Apache", el barrio Villa Soldati y Lugano I y $\|^{19}$, a los que se

\footnotetext{
17 Los "barrios cerrados" y los "countries" son dos clases de urbanización cerrada dotadas de seguridad privada y habitadas por sectores sociales medios y altos que se expandieron en la periferia de la ciudad de Buenos Aires en la última década del siglo XX.

18 "Fuerte Apache" es el nombre con el que se conoce al barrio "Ejército de los Andes", situado en el Partido de Tres de Febrero, Provincia de Buenos Aires. Es un emblema del hacinamiento y deterioro en el que se dejó a caer a los grandes conjuntos habitacionales de interés social. Actualmente se lo asocia además con la delincuencia y la peligrosidad. Comenzó a diseñarse en 1966 durante la dictadura militar de Onganía y sus primeras partes fueron terminadas en 1976 (con un total de 3360 viviendas). Gran parte de sus moradores provienen de villas miseria de la ciudad -como la Villa 31 de Retiro- erradicadas y desalojadas durante los gobiernos dictatoriales. Posee más de 3000 viviendas y aunque fue planificado para 22 mil habitantes, se calcula que actualmente alberga entre 50 mil y 90 mil.

19 "Los barrios "Villa Sodati" y "Lugano I y II" (éste último, oficialmente llamado "General Savio") constituyen también populosos conjuntos habitacionales modernistas de interés social construidos en
} 
asoció con el desorden, el caos, la delincuencia, el hacinamiento y otras representaciones negativas del tipo "ghetto", "aguantadero", "villa de cemento" y "pajarera".

Otro grupo de vecinos centró su rechazo en la categoría "piquetero":

(...) ¿por qué se hace un barrio para los piqueteros? si todos mis hijos se han casado y algunos alquilan y otros están empezando a pagar algo en la provincia. En provincia, porque acá no tuvieron ninguna oportunidad. Y nacieron acá, crecieron acá, estudiaron acá y también trabajan acá (Entrevista a MRE, marzo 2007).

A mí me parece bien que se construyan viviendas, pero ¡podrían ser para gente del barrio, no para piqueteros! Hay gente que alquila, que no tiene dónde ir a vivir. Pero no se les da nada. A los que somos laburantes, que pagamos los impuestos, no. Si así está el país, porque los gobernantes no apoyan a los laburantes, no están con los laburantes (Entrevista a PE, noviembre 2006).

Acá a tres cuadras los piqueteros hicieron terribles departamentos. $Y$ nosotros vivimos pagando, y el gobierno de la ciudad no nos da ni un peso. Nunca nos da nada. Nosotros tenemos que salir a la calle a trabajar y dejar a nuestros hijos con otras personas que los críen. Mientras que a esta gente le dan todo lo que ellos quieren porque se para en la calle y la corta, o por un voto para los candidatos" (Entrevista a EG, febrero 2007).

Y obviamente, acá te conviene hacerte piquetero. Cortás el puente y te dan casa, comida, plata, choripán, el vino, todo.... si sos piquetero conseguís cualquier cosa. Ahora como uno no es sindicalista, ni es político, ni es piquetero, no tenes ningún beneficio. El único beneficio es tu trabajo. ¿Y de qué te sirve? De nada, de nada, de nada" (Entrevista a VVC, febrero 2007).

(..) acá sos piquetero, salís con pañuelos en la cabeza, con palos, hacés lo que quieras, y está todo bárbaro (...) (Entrevista a VE, Febrero 2007).

De diversas maneras e implícita o explícitamente, este grupo de vecinos opuso la figura del piquetero a la del "trabajador digno", al tiempo que vinculó a la primera con la promoción de desórdenes, la haraganería y vagancia. En tanto los piqueteros son trabajadores desocupados que perciben planes sociales que son distribuidos por el Estado, enfatizaron su carácter de "no contribuyentes" al fisco pero sí destinatarios de sus recursos. Los visualizaron como a un grupo de "agitadores" que se encontraría desempleado por propia elección y al que le resultaría más fácil salir a cortar las calles que procurarse su subsistencia trabajando. Es decir, como a un grupo disruptivo, que vive "de arriba", "de regalo", que es mantenido por el Estado a costa de los ingresos que el resto de la ciudadanía aporta al fisco.

las décadas del sesenta y setenta del siglo XX. Por sus dimensiones, superan con creces al complejo habitacional construido por el MTL, ya que como lo señalamos, la capacidad de "Fuerte Apache" alcanza las 50 mil, mientras que el primero ronda las 1500 personas. 
Por otra parte, como se desprende del conjunto de testimonios citados en primer lugar, no faltaron las voces que, de manera irónica, combinaron la primera y segunda categoría -complejo habitacional y piquetero- por medio de expresiones como "country piquetero" y "barrio cerrado" piquetero. Otros vecinos, en cambio, se oponían a la construcción del conjunto habitacional bajo los siguientes argumentos:

"Ahora nos van a importar -nos van a importar- mil vecinos. Porque no es gente de acá, no son propios de acá de capital. Y no la van a mandar a Belgrano ${ }^{20}$. No, la mandan acá" (Entrevista a EA, Septiembre 2006).

"Están metiendo a los piqueteros, a toda esta gente, en la capital. Y nos están ignorando a nosotros" (Entrevista a ED, febrero 2007)

"Nosotros somos los discriminados, porque somos del barrio y de la capital y nos discriminan: no tenemos turno para los hospitales, nuestros chicos no tienen vacantes para ir a la escuela porque está todo ocupado por la gente de la provincia y de la villa. Nosotros somos los damnificados" (Entrevista a EC, febrero 2007).

Ciertos vecinos, por su parte, se centraron en el origen inmigrante de algunos miembros de la agrupación:

El argentino, el nativo, nosotros, ya llega un momento en que lo único que queremos es igualdad de oportunidades, viste. ¿Por qué razón yo estuve tres años desempleada, sobreviviendo miserablemente, cuando veo que gente que viene de afuera tiene un crédito de 800 pesos por mes que paga el gobierno de mi ciudad, con el dinero de mis impuestos, que a mí no me brinda nada? [...] Entonces bueno, en definitiva, el argentino, nativo, normal, común, está acostumbrado a sacrificarse. Nunca agarró un palo para salir a la calle a romper nada, ni destruir, ni prender fuego, ni nada. $Y$ de repente ves que gente que viene y lo hace obtiene una cantidad de ventajas muy superior [...] (Entrevista a MRE, marzo 2007).

Algunos se refirieron incluso a los piqueteros del MTL como "inmigrantes indocumentados" y expresaron igualmente que parecen gozar de "más derechos" que los argentinos aunque provienen de países como Chile, Perú y Bolivia. Otros vecinos, en cambio, fueron un poco más lejos:

“¿Antropóloga sos? no, te equivocaste, acá no hay trabajo para antropólogos, acá son todos animales. Lo más cercano a la civilización, al homo sapiens, son los picapiedras ${ }^{21 " ~(E n t r e v i s t a ~}$ a VE, Noviembre 2006).

"el gobierno tira lo último, lo que le sobra, lo tira acá" (Entrevista a CE, noviembre 2006)

"...estamos acostumbrados a que nos vengan a tirar la basura." (Entrevista a AE, septiembre 2006).

\footnotetext{
${ }^{20}$ Nombre de un elegante y selecto barrio situado en la zona norte de la ciudad de Buenos Aires.

${ }^{21}$ Juego de palabras entre el término "picapiedras" y "piqueteros".
} 
"A mí me trataron de racista porque yo en algún momento dije que dije que el Jefe de gobierno quería poner toda la basura en un solo lugar: debajo de la alfombra. Y que la alfombra eran los barrios del sur" (Entrevista a MRE, mayo 2007). ${ }^{22}$

Otros juicios condenatorios se dirigieron a ciertos comportamientos específicos desarrollados -según los vecinos establecidos- por los integrantes del MTL:

"Las fiestas es otro tema...al principio se quedaban hasta cualquier hora haciendo ruido. Ponían música, prendían los equipos y hacían batifondo hasta altas horas de la madrugada" (Entrevista a ML, noviembre 2006).

"Los trabajadores se juntaban ahí, en la parrillita de enfrente a chupetear...todos los días después de la obra, chupaban cerveza" (Entrevista a AE, septiembre 2006).

"Los vecinos, cada vez que ellos se juntan para ir a una movilización, tenemos que sufrir los doscientos tipos con los bombos, que están media hora ensayando los cantitos. El día que se fueron a Mar del Plata estuvieron hasta las tres de la mañana tomando cerveza, chupando (Entrevista a LA, octubre 2006)".

Otro vecino expresaba:

Esta gente, del movimiento, también metió cuatro o cinco familias de peruanos en un galpón acá enfrente. Y los peruanos vivían mal, sin agua, vivían hacinados ahí (...) Entonces, esta gente empezó a vivir acá enfrente. Y de golpe, de un día para el otro, empezaron a tener problemas. Problemas entre ellos y con algún vecino. Porque la peruana con un vecino tuvo algo que ver, y el peruano con la bebida. $Y$ el summum fue cuando se pelearon entre ellos arriba, el hombre con una mujer y la mujer con otras mujeres y qué se yo, y empezaron a tirar las botellas de arriba, del primer piso del galpón. Y entonces ya fue el colmo... (Entrevista EB, Diciembre 2006)

Por último, cabe remarcar que la mayor parte de los vecinos establecidos incluidos aquellos que manifestaron una actitud más abierta y expectante, a los que nos referiremos luego- afirmaron tener miedo a la inminente mudanza de los adjudicatarios de las viviendas y a compartir el espacio urbano con ellos. Hablando en tercera persona, un vecino sostenía "el vecino esto lo vive como una agresión, el vecino tiene mucho miedo, mucho miedo" (Entrevista a AE, Septiembre 2007). Mientras que por su parte otro decía "al principio, hubo gente aterrorizada" (Entrevista a DE, Noviembre 2006).

Al margen de los matices y diferencias, en todos los casos y actitudes reseñadas, reconocemos algunos aspectos inherentes a la "sociodinámica de la

\footnotetext{
${ }^{22}$ Además de asociar a los piqueteros con los residuos, este conjunto de vecinos trazó una relación de continuidad entre éstos últimos, la ex "Quema de la basura" y el CEAMSE.
} 
estigmatización" que fueron identificados por Elias y Scotson: principalmente, la consideración del grupo de outsiders por los establecidos como un grupo anómico, indisciplinado, indigno de confianza y ruin, de vida licenciosa e incapaz de respetar las normas y los valores compartidas por los establecidos. En efecto, también en este caso los outsiders fueron alternativamente asociados con la bebida y las costumbres relajadas, con el ruido y a la suciedad antes que a la limpieza o pureza, y visualizados -en algunas oportunidades- como un grupo social integrado por seres sub-humanos $^{23}$. Tal como observaran los autores citados, dada su cualidad o carácter disruptivo, el contacto con los outsiders es percibido por los establecidos como contaminante y riesgoso, como una clara amenza de polución y por lo tanto evitado por medio del alejamiento y el distanciamiento (Elias y Scotson, 2000:26-27).

Al mismo tiempo, reconocemos en los casos citados una de las dos estrategias universalmente adoptadas por la humanidad para hacer frente a la "otredad de los otros" que fueron identificadas por Lévi-Strauss (2006). Es decir, la estrategia antropoémica, tendiente al exilio o la aniquilación de los otros. Según Bauman, tal estrategia:

[C]onsistía en vomitar, expulsando a los otros considerados irremediablemente extraños y ajenos: prohibiendo el contacto físico, el diálogo, el intercambio social y todas las variedades de commercium, comensalidad o connubium. Hoy, las variantes extremas de la estrategia émica son, como siempre, el encarcelamiento, la deportación y el asesinato. Las formas superiores y "refinadas" (modernizadas) de la estrategia "émica" son la separación espacial, los guetos urbanos, el acceso selectivo a espacios y la prohibición selectiva de ocuparlos. (Bauman, 2002:109).

Bauman denomina lugares "émicos" a aquellos en los que predomina tal estrategia hacia el otro, y los incluye dentro de los espacios públicos "no civiles" (Bauman 2002:110).

En otros casos en cambio, el desdén y las resistencias hacia los piqueteros se fueron atemperando con el correr del tiempo, a medida que la construcción del complejo habitacional avanzaba y ante la percepción de que se trataba de un proyecto y de una obra "serios", cuya edificación se estaba llevando a cabo correctamente y cuyo diseño y arquitectura resultaban bellos. Sin embargo, más que la aceptación del piquetero en sí, era la expectativa sobre "el tipo" y "la clase de gente" que finalmente resultara "adjudicataria" de las viviendas lo que mitigaba el

\footnotetext{
${ }^{23}$ Nos referimos a las asociaciones establecidas por algunos vecinos entre los piqueteros y la animalidad y la basura.
} 
rechazo de este grupo de entrevistados a los outsiders: es decir, su escepticismo respecto de que los propios piqueteros del MTL fueran también los futuros "adjudicatarios" de las viviendas, y su esperanza acerca de que los moradores efectivos del conjunto habitacional fueran gente trabajadora, digna, "gente de bien", empleada en un trabajo estable, que gozara de "un sueldo" y que tuviera un poder adquisitivo lo suficientemente alto como para cumplir con el pago de las cuotas de devolución del crédito hipotecario y mantener la edificación en condiciones:

\footnotetext{
"Hay gente que se opone. Pero eso...eran galpones, había ratas. Yo prefiero gente a ratas. Siempre la gente es más potable que las ratas" (Entrevista a DE, noviembre 2006).

"Ellos son los que están construyendo. Es una cooperativa, una cooperativa de vivienda que construye. Pero la gente que está trabajando, no son los que van a venir a vivir. Hay que ver la gente que va a venir, la calidad de gente que va a venir...hay que ver" (Entrevista a DCE, noviembre 2006)

"no, esas casas no son para piqueteros. Es demasiado lujo para ellos. Tienen calefón, ya se ven desde afuera los calefones" (Entrevista a VE, Marzo 2007).
}

Reconocemos aquí la segunda estrategia descripta por Lévi-Strauss (1996) para enfrentar la otredad de los otros, la antropofágica, tendiente a la suspensión o aniquilación ya no de los otros sino de su otredad. Según Bauman, dicha estrategia "consiste en la desalienación de las sustancias extrañas: ingerir, devorar cuerpos y espíritus extraños, para convertirlos, por medio del metabolismo, en cuerpos y espíritus idénticos, ya no diferenciables, del cuerpo que los ingirió" (Bauman, 2002:109).

Bauman llama "lugares fágicos" a los sitios en los que predomina esta actitud hacia los otros, y los incluye también dentro de los espacios "públicos no civiles" (Bauman, 2002:110).

De hecho, para este grupo de vecinos establecidos, la aceptación o rechazo de los futuros residentes del complejo habitacional quedaban subordinados a "la clase" y la "calidad" de gente que resultara adjudicataria de las viviendas: más concretamente, a que compartieran y/o adoptaran los valores y conductas reivindicados por ellos (es decir por los establecidos). Como claramente lo expresó un vecino de la zona y dueño de una carnicería local:

Que sea bueno o malo, positivo o negativo, depende en un cien por ciento de la clase de gente que venga a vivir: si viene gente de trabajo, gente que trabaja, que tenga un recibo de sueldo, puede estar bien. Ahora, si a las viviendas se las van a regalar, si viene gente de vida 
fácil, no. Porque a mi me van a venir a comprar pero también a robar (Entrevista a CE, Noviembre 2006).

Si bien más que a una aceptación del otro en tanto que otro, la actitud de este último grupo de vecinos se corresponde con la estrategia antropofágica; excepcionalmente hemos escuchado también algunas voces más ambiguas que fluctuaban entre la aceptación del otro como otro -vale decir como piquetero o miembro del MTL- y la posición antropofágica.

Para una vecina, por ejemplo, el futuro del complejo habitacional y la relación de sus residentes con los vecinos era una casi cuestión de fe " [...] si viene gente buena va a mejorar...todavía no sabemos quiénes van a venir, pero yo tengo fe, ojalá que se revierta, que el barrio mejore...si yo tengo fe" (Entrevista a PE, noviembre 2006).

Por otro lado, es interesante notar que tal como se desprende de los testimonios, a tres o cuatro años de la llegada del MTL a la zona X, los vecinos establecidos aún no contaban con información certera acerca del proyecto llevado adelante por la agrupación ni de su vinculación con un programa oficial de construcción de viviendas de interés social (el PAV, mencionado al comienzo). Tampoco sabían que -dado el carácter autogestionario del programa- los propios integrantes del MTL serían los futuros moradores del complejo habitacional. De hecho, más que en base a información fehaciente y rigurosa, los vecinos establecidos se manejaron siempre en base a sus propios supuestos y conjeturas o bien en función de chismes. Por otra parte, tampoco ningún vecino establecido se acercó a la obra en construcción a consultar al MTL o requerir información sobre los puntos nombrados. Estos hechos nos hablan una vez más del desarrollo de conductas de evitación hacia los outsiders así como de la erección, por parte de los establecidos, de "barreras afectivas" o emocionales para con aquellos, las que cercenaron y bloquearon aún más la posibilidad de acercamiento en un contexto en el que iba disminuyendo su superioridad social y excedente de poder (es decir, los de los establecidos) a la par que iba incrementándose la reputación del $\mathrm{MTL}^{24}$.

\footnotetext{
${ }^{24}$ De acuerdo con Elias y Scotson, no es difícil encontrar ejemplos de "inflexibilidad emocional" y de la erección de "barreras afectivas" en contextos de debilitamiento del poder y la superioridad de los grupos dominantes: por citar sólo uno de los casos comentados por los autores, la abolición de la esclavitud en los Estados Unidos y la equiparación institucional del grupo antes esclavizado al grupo de sus antiguos señores "como conciudadanos de una misma nación", no fue de la mano del debilitamiento de dichas barreras ni del sentimiento de superioridad por parte de los viejos señores
} 
Efectivamente -como lo sugieren los testimonios que citamos en último lugaren el contexto actual ya no podemos hablar de una figuración típicamente dicotómica del tipo establecidos-outsiders, ni afirmar que la zona $X$ se encuentra fracturada en su interior en dos grupos o bandos irreconciliables y monolíticos. Como lo señalamos siguiendo a Elías y Scotson, para que la estigmatización sea posible y eficaz, el grupo de establecidos debe ser internamente cohesivo y encontrarse instalado en posiciones de poder relativamente firmes de las que el grupo de outsiders se encuentra excluido (Elias y Scotson, 2000:23-24).

En la zona $X$, la gradual o relativa desestructuración del modelo binario establecidos-outisders parece vincularse con tales cuestiones. Si bien en un primer momento (hacia 2003 y 2004), los establecidos actuaron en forma mancomunada y como un grupo cohesionado, con el correr del tiempo su solidaridad interna fue debilitándose. Al mismo tiempo, si en un principio éstos pudieron hacer uso y ostentación de su estatus de propietarios, trabajadores y contribuyentes -lo que les confería cierto poder frente a los piqueteros desocupados, "subsidiados" y por ende no contribuyentes y no propietarios-, más allá de esa relativa condición social superior $^{25}$, al momento de la llegada del MTL ya no constituían un grupo firmemente instalado en posiciones de poder sino más bien lo contrario: es decir, un grupo social pauperizado y desclasado. Según lo indicamos, en ese momento la zona X podía ser pensada en términos de un espacio urbano residual y decadente, simbólicamente distanciado del resto del barrio de Parque Patricios, signado por un acusado proceso de desindustrialización y poblado por familias de clase media empobrecidas que experimentaron un agudo y vertiginoso descenso social ${ }^{26}$.

Desde luego, esos fenómenos tuvieron un influjo negativo en la identidad de los vecinos establecidos, quienes vieron paulatinamente debilitada su autoestima y trastocado su sentimiento de pertenencia al lugar así como su cohesión y solidaridad grupal $^{27}$. Aunque el potencial organizativo y la cohesión de los vecinos establecidos

sino más bien de su reforzamiento y endurecimiento, como mecanismo reactivo a la nueva situación de igualdad jurídico-política (Elias y Scotson 2000:25).

${ }^{25}$ Decimos estatus superior relativo porque en verdad gran parte de los miembros del MTL se encontraban empleados en forma asalariada en la obra en construcción y eran por ende trabajadores y contribuyentes.

${ }_{26}$ En un grado no desdeñable y con algunos matices -dado el débil mejoramiento de su infraestructura y equipamiento al que nos referimos antes- la zona $X$ puede ser pensada así aún en la actualidad.

${ }^{27}$ Como ya lo señalamos también, debe recordarse que, en una actitud no exenta de nostalgia, los establecidos suelen definir y caracterizar a la zona X más en términos de lo que fue en el pasado que 
lejos estuvieron de verse totalmente extinguidos (como lo demuestran las múltiples acciones de protesta que organizaron a fin de rechazar al MTL, las que incluyeron reuniones con ciertos funcionarios en la Legislatura de la ciudad), si revelaron no ser lo suficientemente fuertes como para doblegar a los del MTL.

Todo lo contrario ocurrió con dicha agrupación, cuyos integrantes fueron incrementando su entusiasmo y sentimiento de pertenencia al movimiento con el correr del tiempo, y reforzando su solidaridad interna y capacidad organizativa a medida que iban recogiendo los frutos de su proceso de lucha y movilización y materializándolos en la construcción del complejo habitacional. Ciertamente, un factor trascendental en la desestructuración de la figuración dicotómica establecidosoutsiders fue que el MTL reveló ser un grupo mucho más cohesionado que los establecidos. Y no sólo eso sino que además fue adquiriendo cierta reputación y mayor legitimidad ante el resto de la sociedad, por la belleza y alta calidad de la obra que se encontraba construyendo, por la capacidad de organización y gestión que mostró el movimiento para llevarla adelante y por lo "exitoso de la experiencia" (los principales diarios de la capital -La Nación, Página 12 y Clarín- publicaron notas acerca de ello).

Tal como lo advierten Elias y Scotson, la utilización del modelo establecidosoutsiders como correspondiente a una relación de carácter estático no debe extenderse más allá de una etapa inicial ya el equilibrio de poder entre los grupos puede variar y resultar modificado (Elias y Scotson, 2000:36).

Sin embargo, todo ello no significa que la zona $X$ haya devenido en un espacio público. Siguiendo a Giglia (2000) un espacio público sólo existe como tal si logra trastornar la relación de equivalencia entre una identidad colectiva y un territorio. Mostraremos ahora cómo a pesar de la relativa desestructuración de la figuración dicotómica establecidos-outsiders, la zona X no puede ser caracterizada como un espacio público en sentido estricto, en tanto la única "ideología de identidad" (Prats, 1997) admitida allí continúa siendo la de los establecidos.

de lo que es en la actualidad, y destacar la pujanza y vitalidad de la zona $\mathrm{X}$ así como la época en que ellos mismos gozaban de una mejor posición social y económica. 


\section{De recurso a espacio público no civil: el micro acontecimiento "Villa El cartón"}

Si como lo indicamos, la esencia de la civilidad "es la capacidad de interactuar con extraños sin atacarlos por eso y sin presionarlos para que dejen de serlo o para que renuncien a algunos de los rasgos que los convierten en extraños" (Bauman, 2002:113), y si el espacio público es el espacio paradigmático en el que ello ocurre, la zona X no puede definirse como tal. Representa más bien un espacio "público no civil" (Bauman 2002:113), cuya nota distintiva es la redundancia de la interacción. Se trata de espacios que son frecuentados por grupos sociales diversos y que si bien son públicos, han sido despojados de la capacidad de unir e integrar las diferencias. Son, en concreto, lugares en los que la actitud de indiferencia hacia el otro se ha institucionalizado al punto que ese otro extraño y desconocido deja de ser registrado. Así, aunque no imposibilitan toparse ni cruzarse con otros diferentes, los espacios públicos "no civiles" permiten al menos evitar el trato y la agotadora comunicación con ellos.

En la zona $X$, dicha incapacidad para dialogar e interactuar con el otro se puso claramente de manifiesto cuando en la mañana del lunes 26 de febrero de 2007 algunos medios masivos de comunicación dieron a conocer la decisión del gobierno de la ciudad de trasladar a los habitantes de un asentamiento recientemente incendiado, situado en el barrio de Villa Soldati y denominado "Villa EI Cartón"28 a una ex fábrica del barrio de Parque Patricios ubicada precisamente en la zona X. Se trataba del edificio de una ex fábrica localizada a sólo dos cuadras del complejo habitacional del MTL.

Por la mañana temprano, algunos vecinos establecidos observaron movimientos atípicos en la citada ex fábrica, que se encuentra abandonada desde

\footnotetext{
${ }^{28}$ El asentamiento "Villa El Cartón", localizado debajo de la Autopista Cámpora (AU 7, barrio de Villa Soldati), se incendió el 8 de febrero de 2007. Allí vivían una 470 familias aproximadamente. Dichas familias, que a causa del fuego perdieron sus precarias casillas y todas sus pertenencias, fueron provisoriamente trasladadas por el gobierno local a un parque situado también en un barrio empobrecido del sur de la ciudad (el Parque Roca) y ubicadas en carpas y tiendas. Al cabo de unos días, a causa de un temporal, las carpas se desarmaron. Las estructuras metálicas que las sostenían volaron y golpearon mortalmente a una mujer. El gobierno local se vio obligado nuevamente a trasladar a las familias a otro espacio. Tanto en el barrio de Villa Soldati (barrio en el que residían inicialmente y en donde el poder público procuró re-ubicarlos) como en el de Parque Patricios hubo movilizaciones y protestas vecinales ante la noticia del posible traslado de los ex habitantes de "Villa El cartón".
} 
hace años. Advirtieron la presencia de personal del gobierno local (al que identificaron por su vestimenta que lleva la sigla GCBA) realizando allí tareas de limpieza y acondicionamiento. Según los múltiples testimonios recogidos ese día entre los vecinos; hacia el mediodía, los habitantes de "Villa El Cartón" se encontraban en los alrededores de la ex fábrica y en el Parque de los Patricios, con sus colchones y algunas pertenencias, aguardando que el personal concluyera con las tareas de limpieza para alojarse allí.

Pues bien, tampoco en este caso la reacción se hizo esperar, al punto que la noticia que circulaba por los medios masivos de comunicación hacia las 17 horas ya no era la de la mañana sino otra que repetía "tensión en Parque Patricios", "vecinos incendian una fábrica", "se oponen al traslado de los habitantes del asentamiento Villa El Cartón" al barrio.

Efectivamente, movilizados y enardecidos por la noticia, y al son de los cánticos "con el barrio no se jode" y "cada uno en su lugar", los vecinos establecidos habían encendido dos fogatas en señal de protesta en la puerta de la fábrica. Ello provocó en primer lugar la llegada de los bomberos, en segundo lugar la de la policía y en tercer lugar la de los principales medios masivos de comunicación de radio y televisión.

\begin{abstract}
Nos enteramos de que quieren traer a toda la gente....a las familias de Villa el Cartón...que las iban a traer acá: a meter en ese galpón de toda la manzana [...] Nosotros no decimos que la gente no tenga que tener una vivienda digna, pero no es el caso que nos las pongan acá a nosotros. No queremos que se convierta esto en un ghetto. Lo que pedimos es que a la gente le den vivienda pero no acá. La inseguridad ya es terrible. Hablamos con el comisario y dice que tienen poco personal, ¿que nos espera después con 3 mil familias más acá? Nosotros lo que queremos es que acá no se meta más nadie, no vamos a permitir que se meta más gente acá. (Entrevista a VEH, Febrero 2007)
\end{abstract}

Las acusaciones que los vecinos lanzaron contra los ex habitantes de Villa El Cartón fueron diversas y una vez más se vincularon con los rasgos inherentes a la "sociodinámica de la estigmatización" (Elias y Scotson, 2000) a los que nos referimos antes. Interesa remarcar aquí las asociaciones trazadas por no pocos establecidos entre la posible instalación de los ex habitantes de Villa El Cartón en la zona x y la anterior llegada del MTL.

Les salió el tiro por la culata. Porque cuando vinieron los piqueteros, cuando salimos ya era tarde. Pero hoy salimos antes. ¿Por qué salimos antes? Porque el rumor ya se había 
escuchado a la mañana en televisión. Alguien dijo que los traían, yo lo escuche en la Mega ${ }^{29}$ a la tarde, tipo una de la tarde, la gente ya empezó a comentar "guarda que vienen los cartoneros, los cartoneros" ...y estuvimos todos acá a las 6 de la tarde (Entrevista a VEZ, Febrero 2007).

Mientras que otra vecina, sosteniendo a su hija de seis años en brazos y enfadada por llegada de la policía para custodiar la movilización vecinal, expresaba:

\begin{abstract}
Es una una falta de respeto porque, escuchame, acá sos piquetero, salís con pañuelos en la cabeza, con palos, hacés lo que quieras, y está todo bárbaro, estos no aparecen (dirige la mirada al personal policial). Sos gente común, civil, laburante -porque yo, todo lo que tengo, me lo gané- ¿me entendés? y te mandan a esta gente (mira nuevamente a los efectivos policiales). Claro, ellos no tienen la culpa porque es su laburo. Pero hoy cuando los bajaron, a los tipos no les importó si había chicos, si no había chicos, o lo que fuera. Entonces ¿donde carajo está el gobierno de la ciudad para mí? ¿para mí dónde está? (Entrevista a VE, Febrero 2007).
\end{abstract}

Al día siguiente, los vecinos establecidos volvieron a reunirse en la puerta de la ex fábrica con el fin de "montar guardia" e impedir el posible ingreso de gente al lugar, de realizar una asamblea para organizar la lucha y de distribuir un volante con la siguiente inscripción:

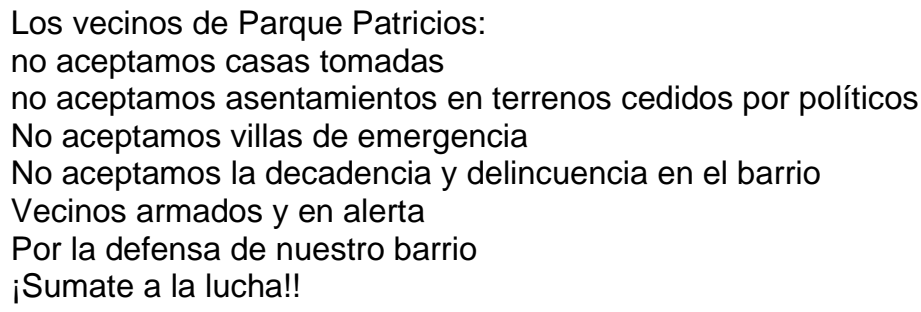

Nuevamente, la zona $X$ era objeto de disputas. Nuevamente, se perfilaba una figuración dicotómica del tipo "establecidos"-"outsiders" en la que éstos últimos eran considerados por los primeros como seres humanamente inferiores (Elias y Scotson, 2000). Sólo que en esta oportunidad, los outsiders no llegaron a establecerse allí por obra y re-acción de los "establecidos"... (Elias y Scotson 2000).

\title{
Conclusiones
}

Las dinámicas registradas en la zona $X$ nos han permitido vislumbrar, a escala local, la relevancia de ciertos atributos de la vida urbana entre los que se destacan la civilidad y la urbanidad, así como de los espacios en los que dichos

\footnotetext{
${ }^{29}$ Nombre de una emisora de radio local.
} 
atributos se despliegan -es decir, los espacios públicos- y lo que ocurre cuando los mismos se debilitan y resquebrajan. Las referidas dinámicas nos han permitido vislumbrar además algunos de los rasgos consignados por ciertos autores (Bauman, 2002; Donzelot 2004; Giglia, 2000; Gorelik, 2004; Mongin, 2006; Zukin, 1995) como característicos de la vida urbana contemporánea, o por lo menos como rasgos muy extendidos y generalizados en ella: la creciente incapacidad para dialogar e interactuar con el otro, de negociar las diferencias, la institucionalización del miedo al otro y al extraño, al que se asocia cada vez más con la marginalidad y la exclusión, y la "defensa de la comunidad" (Bauman, 2002:102) -y ya no del "bien común"representada en términos de un "nosotros" puro e incontaminado frente a un "otro" amenazante, y definida más por sus límites que por sus contenidos, como un fin en sí mismo. Tal como lo expresa Sennet, mantener la comunidad se transforma en un fin en sí mismo, y la purga de todos aquellos que no pertenecen a la comunidad se convierte en una de sus tareas prioritarias (Sennet, 1978).

Pero fue Mary Douglas (1973) quien puso de manifiesto que en las sociedades primitivas, todo aquello que se sitúa en los márgenes del cuerpo social es considerado como impuro y potencialmente amenazante. Sin embargo, como lo ha notado Bernard y como surge de nuestro trabajo, tales representaciones asociadas a la impureza y suciedad pueden hallarse también en contextos contemporáneos, por cuanto las creencias y valores ligados a la impureza pertenecen a la esfera de la segregación (Bernard, 1994): según lo intentamos mostrar, en la zona X la "defensa de la comunidad" (Bauman, 2002:102) se efectuó por medio de los diversos estigmas endilgados a los outsiders por los establecidos, los que cubrieron un espectro muy amplio que iba desde un rechazo más o menos moderado del otro y su conceptualización en términos racistas y como elementos "patógenos" o "contaminantes", hasta la negación misma de su humanidad.

Por otra parte, los procesos acontecidos en la zona $\mathrm{X}$ permitieron observar además que, lejos de ser natural o inherente a ciertos grupos sociales, la capacidad de estigmatizar es dinámica, cambiante y contingente, y que está en función de los niveles organizativos, de cohesión e integración de los grupos sociales. Fue precisamente eso -su alto nivel cohesivo- lo que permitió al MTL "ganarle la batalla" a los establecidos y llevar adelante y concluir con el proceso de edificación de las viviendas sin mayores dificultades, pese a la inicial resistencia opuesta por aquellos. 
De igual modo, fue el haber actuado en forma mancomunada, solidaria, como grupo compacto y carente de fisuras internas, así como haber reaccionado con celeridad, lo que posibilitó a los vecinos establecidos rechazar con "éxito" el establecimiento de los ex habitantes de Villa El cartón en la zona X.

En tal sentido, los procesos desplegados en la zona $X$ dan cuenta del incremento de la segregación y la fragmentación socio espacial. Según lo sostuvimos al comienzo, en la ciudad de Buenos Aires, la recualificación y estetización de algunos espacios urbanos ha sido paralela a la desvalorización y la marginalización de otros. Atendiendo a ese doble movimiento, consideramos que sería por demás simplista y reduccionista concluir este trabajo tildando de racistas y discriminatorias a las prácticas de los vecinos establecidos en la zona X contra los outsiders, aún cuando podamos creer que lo son. Al respecto, cabe preguntarse si cuando los vecinos establecidos expresan "somos ciudadanos de cuarta" o "a los piqueteros no los van a mandar al barrio de Belgrano, los mandan acá" (Entrevista a EA, Septiembre 2006), no están haciendo otra cosa que denunciar desde el sentido común el carácter diferencial, "segregacionista" y clasista de ciertas políticas urbanas y del modelo de planeamiento urbano hegemónico en el contexto contemporáneo. Modelo que implícita o explícitamente tiende a sectorizar el espacio urbano, embelleciendo, patrimonializando y valorizando algunas zonas de la ciudad, y "expulsando" la pobreza de allí, concentrándola en otras zonas e invisibilizándola. El aumento de la conflictividad social y la incapacidad de negociar las diferencias, el temor hacia el otro diferente y desconocido, una sociedad cada vez más enfrentada entre establecidos y outsiders, pueden ser el correlato más o menos directo de la consolidación de estas nuevas formas de "hacer ciudad".

A modo de cierre, quisierámos destacar también que aunque la intensificación de la segregación y la fragmentación son innegables, las lecturas del espacio urbano en términos de dualidad o bien en términos de "tres velocidades" (Donzelot 2004) pueden resultar algo esquemáticas. Así, aunque, la zona X puede ser pensada en términos de un gran fragmento urbano signado por el movimiento de la relegación; los micro-procesos de diferenciación y fragmentación internos y las micro-disputas suscitadas entre vecinos "establecidos" y "outsiders" aquí descritas obligan a complejizar un tanto la mirada. En otros términos: las dinámicas registradas en la zona $X$ testimonian que los espacios atravesados por los grandes movimientos 
identificados por Donzelot y otros autores citados al comienzo (Aguilar, 2005; Ciccolella, 1999; Sarlo, 1996) se encuentran a su vez cruzados por diversas microvelocidades. Como lo ha observado el propio Mongin, más que ante ciudades de tres velocidades, nos encontramos ante metrópolis atravesadas por velocidades múltiples (Mongin 2006:248). Consideramos que la antropología constituye una de las disciplinas mejor equipadas para abordar y aprehender dichas micro-velocidades (cfr. Bernard 1994) y esperamos que el presente trabajo represente una contribución en tal sentido.

\section{Referencias bibliográficas}

Aguilar, Marta (2005) Devenir de supuestos: de los "universales" a los "criollos"”. En Buenos Aires a la deriva. Welch Guerra, Ed. Buenos Aires: Biblos.

Auyero, Javier (2001). Introducción. Claves para pensar la marginación. En Parias Urbanos. Marginalidad en la ciudad a comienzos del milenio. Wacquant, Loic. Buenos Aires: Manantial.

Bernard, Carmen (1994) Ségrégation et anthropologie, anthropologie de la ségrégation. Quelques éléments de réflexion. En La ségrégation dans la ville. Carmen Bernard, Ed. Paris: L'Harmattan.

Bauman, Zygmunt (2002). Modernidad líquida. Buenos Aires: Fondo de Cultura Económica.

Carman, María (2006). Las trampas de la cultura. Los "instrusos" y los nuevos usos del barrio de Gardel. Buenos Aires: Paidós.

Ciccolella, Pablo (1999). Globalización y dualización en la Región Metropolitana de Buenos Aires. Grandes inversiones y reestructuración socioterritorial en los años noventa. Revista Eure 76(25): 5-27.

Donzelot, Jacques (2004). La ville á trois vitesses: relégation, périurbanisation, gentrificación urbaine. Revue Esprit, 263:14-39.

Douglas, Mary (1973) Pureza y peligro: un análisis de los conceptos de contaminación y tabú. Madrid: Siglo XXI.

Elias, Norbert y Scotson, John (2000). Os estabelecidos e os outsiders. Sociologia das relaçoes de poder a partir de uma pequena comunidade. Rio de Janeiro: Zahar.

Giglia, Angela (2000). ¿Es posible la urbanidad en las megaciudades?. Conferencia presentada en Séminaire Prisma 3, Toulouse, 23 de Marzo.

Girola, María Florencia (2007). El surgimiento de la mega-urbanización Nordelta en la Región Metropolitana de Buenos Aires: consideraciones en torno a las nociones de ciudad-fragmento y comunidad purificada. Revista de Estudios Demográficos y Urbanos, Centro de Estudios Demográficos y de Desarrollo Urbano. El Colegio de México.2 (22): 363-397.

Gorelik, Adrián (2004). Miradas sobre Buenos Aires Historia cultural y crítica urbana. Buenos Aires: Siglo XXI.

Herzer, Hilda (2004). Riesgo y renovación: el papel de las organizaciones sociales. En Fragmentos sociales. Problemas urbanos de la Argentina. Cuenya Beatriz, Fidel Carlos y Hilda Herzer, Coords. Buenos Aires: Siglo XXI.

Kessler, Gabriel (1998). L'appauvrissement des classes moyennes en Argentine. Tesis doctoral, École des Hautes Études en Sciences Sociales

Kociatkiewicz, Jerzy y Kostera, Monika (1999). The anthropology of empty space. Qualitative Sociology, 1: 43-48. 
Lacarrieu, Mónica (2007). Habitants de la Boca a Buenos Aires. El conventillo: ¿habitatge, recurs o paisatge cultural?. Revista d'Etnologia de Catalunya, 31: 44-58.

Lacarrieu, Mónica (2005). Nuevas políticas de lugares: recorridos y fronteras entre la utopía y la crisis. En Buenos Aires a la deriva. Welch Guerra, Ed. Buenos Aires: Biblos.

López, Laura (2003). Actuación, patrimonio e identidad negra. El caso de las llamadas de tambores en San Telmo. En Temas de Patrimonio 7. El espacio cultural de los mitos, ritos, leyendas, celebraciones y devociones. Buenos Aires: Comisión para la Preservación del Patrimonio Histórico Cultural de la Ciudad de Buenos Aires.

Mongin, Olivier (2006). La condición urbana. La ciudad a la hora de la mundialización. Buenos Aires: Paidós.

Neiburg, Federico (2000) Apresentacao à Edicao Brasileira. En Os estabelecidos e os outsiders. Sociologia das relaçoes de poder a partir de uma pequena comunidade. Elias, Norbert y Scotson, John. Rio de Janeiro: Zahar.

O' Connor, Justin y Wynne, Derek (1997) Das Margens para o Centro. Produçao e consumo de cultura em Manchester. En Ciudades, Cultura e Globalizaçao. Ensaios de Sociología. Carlos Fortuna Org. Brasil: Celta Editora.

Prats, Llorenc (1997). Antropología y Patrimonio. Barcelona: Ariel.

Prévot Schapira, Marie France (2000). Segregación, fragmentación, secesión: hacia una nueva geografía social en la aglomeración de Buenos Aires. Revista Economía, Sociedad y Territorio, 7(2): 405-431.

Sassen, Saskia (1999). La ciudad global. Nueva york, Londres, Tokio. Buenos Aires: Eudeba

Sarlo Beatriz (1996). Instantáneas. Medios, ciudad y costumbres en el fin de siglo. Ariel: Buenos Aires.

Sennet, Richard (1978). The Fall of Public Man: on theSocial Psychology of Capitalism. Vintage Books: Nueva York.

Signorelli, Amalia (1999). Antropología Urbana. Barcelona: Anthropos.

Svampa, Maristella y Pereyra Sebástián (2003). Entre la ruta y el barrio. La experiencia de las organizaciones piqueteras. Biblos: Buenos Aires

Thomasz, Ana G. (2007). Políticas culturales en el seno de movimientos político sociales "piqueteros". Voces Recobradas. Revista de Historia Oral, 23: 52-62.

Zukin, Sharon (1995). The Culture of Cities. Oxford: Blackwell. 